\title{
Understanding Regional Energy Poverty in Japan: A Direct Measurement Approach
}

\author{
Shinichiro Okushima \\ Graduate School of Systems and Information Engineering, University of Tsukuba, \\ 1-1-1, Ten-nodai, Tsukuba-science-city, Ibaraki, 305-8573, Japan. \\ E-mail: okushima@sk.tsukuba.ac.jp
}

\begin{abstract}
This study examines the regional characteristics of energy or fuel poverty in Japan through a new approach, i.e., evaluating energy poverty via the direct measurement of energy service usage. This measure is a kind of relative poverty measure in calorific value, with multiple thresholds reflecting the diverse energy needs of households. The analysis sheds light on several unexplored issues in previous literature. Most notably, the result emphasizes the role of kerosene (heating oil) in securing warmth in winter, especially in the northern regions, and highlights an "energy poverty premium" in Japan on the unit cost of energy (per amount of heat). This study also suggests that the ongoing energy transition from fossil fuels to renewables should be promoted carefully with due consideration to the detrimental impact on the energy poor.
\end{abstract}

Keywords: Climate, Direct measurement, Energy justice, Energy poverty, Energy service, Energy vulnerability, Fuel Poverty, Japan, Multiple thresholds, Poverty premium

\section{Introduction}

In recent years, there has been burgeoning interest in energy or fuel poverty in developed countries. ${ }^{1}$ Many studies have been published in European countries such as Austria (e.g., Brunner et al., 2012), France (e.g., Legendre and Ricci, 2015; Imbert et al., 2016; Fizaine and Kahouli, 2019), Germany (e.g., Heindl, 2015; März, 2018), Greece (e.g., Santamouris et al., 2013; Papada and Kaliampakos, 2016), Italy (e.g., Fabbri, 2015), and Spain (e.g., Aristondo and Onaindia, 2018; Romero et al., 2018), to say nothing of the UK, a pioneer in this field (e.g., Boardman, 2010; Hills, 2012).

\footnotetext{
1 This study uses the term "energy poverty" synonymously with "fuel poverty," following recent literature in this field (e.g., Bouzarovski and Petrova, 2015; Bouzarovski, 2018), and specializes in the problem of energy poverty in developed countries. On the energy poverty problem in the context of developing countries, see, for example, González-Eguino (2015) or IEA (2010).
} 
Even non-European countries such as Australia (e.g., Poruschi and Ambrey, 2018), New Zealand (e.g., Howden-Chapman et al., 2012; O’Sullivan et al., 2015), and Japan (e.g., Okushima, 2016, 2017) have contributed their share.

Energy poverty can be defined as "the inability to attain a socially and materially necessitated level of domestic energy services” (Bouzarovski and Petrova, 2015). The concept of energy poverty is concerned with domestic energy service usage, which represents an essential part of a person's achieved well-being. ${ }^{2}$ Moreover, energy poverty is intrinsically multidimensional, and closely related to energy injustice (Walker and Day, 2012; Jones et al., 2015; Sovacool, 2015; Jenkins et al., 2016; Sovacool et al., 2016). Energy poverty is generally recognized as a distributional justice issue, which is one of the tenets of energy justice, and a phenomenon of energy injustice at the end-use stage of energy system (e.g., Walker and Day, 2012; Bouzarovski and Simcock, 2017). ${ }^{3}$

This study examines the regional characteristics of energy poverty in Japan for the first time. Previous literature has often overlooked regional or spatial aspects of energy poverty, despite their potential importance (Bouzarovski and Simcock, 2017; Robinson et al., 2018ab). Although some studies undertake regional assessments of energy poverty within countries, they often focus on the geographical disparities of energy poverty prevalence. For example, some studies show higher energy poverty rates in regions with colder climates (e.g., Papada and Kaliampakos, 2016). Other studies reveal high prevalence of energy poverty in rural and peripheral regions due to inefficient housing stock and lack of access to affordable fuels (e.g., Bouzarovski, 2018).

Despite the valuable information derived from existing scholarship, the question of how to evaluate regional energy poverty, with full consideration of underlying drivers that affect household energy needs in each region, remains open (Bouzarovski and Simcock, 2017). For instance, the difference in heating needs mostly explains the high prevalence of energy poverty in cold climates. In such cases, the dominant influence of climatic factors possibly hides the presence of other vulnerability factors, such as socio-demographic or dwelling factors, within a region. ${ }^{4}$ To deal with the problem, it is necessary to implement poverty measures that can adequately treat variations in household energy needs, e.g., heating in winter, which inevitably depend on the living place, socio-demographic or dwelling factors.

\footnotetext{
${ }^{2}$ While the notion of "well-being" is ambiguous, this study refers to Amartya Sen's definition. Sen (1992, p.39) writes, "the well-being of a person can be seen in terms of the quality (the 'well-ness', as it were) of the person's being." In his theory, well-being can or should be evaluated via "functionings" - beings and doings that people value, such as being in good health - and "capabilities" - the various combinations of functionings that the person can achieve (Sen, 1985; Alkire et al., 2015). Day et al. (2016) also reexamine energy use and energy poverty within Sen's capabilities framework.

${ }^{3}$ From the different viewpoint, Yenneti et al. (2016) investigate an energy injustice issue that occurs at the production stage of energy system, i.e., the dispossession of vulnerable social groups from livelihoods through solar energy implementation in India.

${ }^{4}$ In this study, the term "vulnerability factors" indicates the drivers that increase the risk of a household falling into energy poverty, as in Bouzarovski and Petrova (2015) or Robinson et al. (2018b).
} 
To date, various types of measures have been proposed for gauging energy poverty (e.g., Okushima, 2017; Romero et al., 2018). Nevertheless, it cannot be said that existing measures can evaluate regional energy poverty after controlling for the vulnerability factors, such as climate. Typically, existing poverty measures are national-scale estimators with a uniform threshold. As Robinson et al. (2018ab) suggest, such types of measures cannot adequately treat a constellation of spatially-related vulnerability factors as well as the diverse energy needs of households within a country.

Moreover, the majority of measures, such as the classical 10\% indicator (Boardman, 1991) or the new official UK Low Income High Cost (LIHC) indicator (Hills, 2012), are affordability measures that assess energy poverty on the basis of energy expenditure and income. In other words, such expenditure-based, affordability measures gauge household affordability of "adequate energy services,” but by no means the underconsumption of energy services itself. One famous drawback of (actual) expenditure-based measures is the difficulty in correctly identifying the energy poor in the presence of restriction practices, that is, restraining energy use below a comfort level (Liddell et al., 2012; Moore, 2012; Legendre and Ricci, 2015). Liddell et al. (2012) demonstrate a larger disparity between actual energy expenditure and energy needs to spend, especially in colder regions. ${ }^{5}$

Against this background, this study presents a new approach to measuring energy poverty, which is considerably different from conventional ones. This approach has the unique feature of measuring energy poverty in achieved calorific value, via the direct energy service usage of each household. In other words, this new approach defines poverty thresholds via energy use in joules, rather than via energy expenditure such as traditional measures, thereby, allowing us to avoid misidentification (false negative), e.g., by restriction practices of the poor. In addition, this new measure can set multiple poverty thresholds with a new concept of "type," enabling us to consider a huge variety of spatial, socio-demographic, and dwelling vulnerability factors that affect the risk of falling into energy poverty.

This study examines Japan as a case study, although it is possible to apply the methodology and results to other countries as well. The remainder of this paper is structured as follows. Section 2 provides an overview of Japanese energy poverty and discusses regional differences in the context of energy poverty. Especially, since Japan has a wide variety of climates, a suitable measure is necessary, which can treat the difference in energy needs according to climate to evaluate regional energy poverty appropriately. Section 3 explains the new methodology for gauging (multidimensional) energy poverty via a direct measurement of energy services usage. This new measure has two-fold features. The first is to evaluate the underconsumption of energy services in calorific value directly, rather than measuring the energy affordability of households like previous measures. The new measure allows us

\footnotetext{
${ }^{5}$ The alternative measures they proposed, such as the median expenditure (share) approach (Liddell et al., 2012) or the Minimum Income Standard (MIS) approach (Moore, 2012; Romero et al., 2018), are also expenditure-based measures.
} 
to gauge the achievement of their well-being in a more direct manner. Second, it enables multiple poverty thresholds, rather than a uniform threshold in existing measures. Multiple thresholds enable the new measure to deal with the diverse energy needs of households within a country or region more adequately. Section 4 presents the results and discusses the findings. The analysis shows that the multiple thresholds approach is more suitable than a uniform threshold in evaluating regional energy poverty in Japan. The result also indicates the essential role of kerosene in securing warmth, especially in northern Japan, and suggests the presence of an "energy poverty premium” in Japan, i.e., the unit cost of energy for all energy services is higher for the energy poor. The final section provides the concluding remarks and policy implications. It discusses the current policies in Japan from the perspective of energy poverty, and finally, presents the unsolved issues in this study.

\section{Energy poverty in Japan: historical and regional perspectives}

There is still not much scholarship on energy poverty in developed nations other than in Europe. Japan is no exception, although some previous studies analyze the energy poverty phenomenon in Japan. Okushima (2016) describes the energy poverty situation in Japan since the 2000s, using the traditional $10 \%$ indicator, showing that energy poverty gradually deteriorated in the 2000s, especially after the 2011 Great East Japan Earthquake (GEJE) and the Fukushima nuclear accident. Okushima (2017) develops a new multidimensional energy poverty index (MEPI), comprising the three dimensions of energy poverty, namely, energy costs, income, and energy efficiency of housing, suggesting that the situation for mother-child and single-elderly households, in particular, has been serious since the GEJE. Moreover, both studies emphasize the harsh conditions of energy poverty in winter.

Fig. 1 is the so-called vulnerability index, developed by Okushima (2016), in which "vulnerability" means the level of households' risk of falling into energy poverty at the macro level. This is a simple index composed of domestic energy prices and income, and helps understand the historical trend of the energy poverty situation. Fig. 1 depicts a continuous rise in Japan's vulnerability level after 2000 until a fall in 2015-16, due to a plunge in international energy prices, and an increase again in 2017. The present level of vulnerability is still high on a medium to long-term basis.

Although previous studies such as Okushima (2016, 2017) do examine energy poverty in Japan, information on the regional characteristics of energy poverty in Japan is scarce. As stated in Section 1, existing studies have examined the problem of energy poverty mainly from the socio-economic and socio-demographic aspects, relegating the spatial aspects of energy poverty to the periphery (e.g., Bouzarovski and Simcock, 2017). The same is true in the Japanese case. The above-mentioned studies only provide national estimates using expenditure-based measures, and do not examine the phenomenon in detail from the spatial or regional perspective. 
In fact, more than other developed nations, it is necessary to examine the energy poverty phenomenon in Japan, especially through the spatial or regional lens. Traditionally, e.g., in governmental statistics, Japan comprises 10 regions (Table 1\&Fig. 2). These 10 regions are further split into 47 prefectures, which are the first tier of administrative units in Japan. As in Table 1, over half of the total population is concentrated in the three major metropolitan areas, which are the most affluent and developed areas in the country, such as Kanto (-Koshin), Kinki, and Tokai regions. At the prefectural level, the population density is highest in Tokyo, followed by Osaka, Kanagawa, Saitama, and Aichi, which are all included in the three major metropolitan areas. Conversely, other rural regions or prefectures have low population densities; the lowest in Hokkaido, followed by Iwate and Akita, which are all included in the northernmost regions of Japan. Prior literature argues that residents living in low population density areas are more likely to experience energy poverty (e.g., Bouzarovski, 2018).

Furthermore, as is well known, Japan is one of the countries with the widest varieties of climatic conditions in the world. ${ }^{6}$ Japan stretches from north to south, with four distinct seasons and a range of climatic conditions from Hokkaido in the subarctic zone in the north to Okinawa in the subtropical zone in the south (Fig. 2). The northern part of Japan has warm summers and very cold winters with heavy snow, while the southern part has hot and humid summers and mild winters with no snow. Even the middle of Japan presents a variety of climatic conditions, but generally in-between the two extremes.

Climate has a significant relationship with energy vulnerability - the risk of falling into energy poverty. Many studies indicate that different climates create different energy needs for residents (e.g., Liddell et al., 2012). Typically, colder climates need more energy for space and water heating. For example, the Spanish study by Romero et al. (2018) emphasizes the dependence of energy poverty rates on climatic factors, and the Greek study by Papada and Kaliampakos (2016) shows that energy poverty rates are far higher in colder climate zones and mountainous areas due to lower temperatures. Section 4 shows large disparities in energy use across the Japanese regions. Notably, when traditional measures are applied in the case of Japan, which has a wide range of climatic conditions, it is concerned that the dominant influence of climatic factors brushes aside any other types of vulnerability factors.

In addition to climate, regional differences exist in a variety of vulnerability factors influencing the risk of energy poverty. The differentials in household incomes between regions are evidently important in the context of energy poverty, as well as the spatial differences in energy prices (Walker et al., 2015; Bouzarovski and Simcock, 2017). In the energy poverty literature, Robinson et al. (2018b) show that the spatial distribution of households with particular energy needs (e.g., households with elderly persons or young children, or people with disability or long-term illness) varies

\footnotetext{
${ }^{6}$ Japan Meteorological Agency (JMA) (http://www.data.jma.go.jp/obd/stats/data/en/index.html).
} 
substantially across regions in England. Roberts et al. (2015) illustrate the spatial variation across the regions in the UK in terms of housing stock and gas grid connections. The same is true even for the behavioral culture of energy use; for example, bathing culture differs even across Japanese regions, as we all know the difference between Japan and Western countries (Westrom, 2018). The information derived from the above studies, albeit mostly conducted in other countries, is of great value in evaluating the regional characteristics of energy poverty in Japan.

\section{Methodology}

This study develops a new approach to measuring energy poverty, which can appropriately deal with the differences in energy needs according to spatial, socio-demographic, and dwelling factors. The method directly measures whether a household is unable "to have adequate energy services" (Boardman, 1991); in other words, it directly measures whether a household is unable "to attain a socially and materially necessitated level of domestic energy services” (Bouzarovski and Petrova, 2015). Bouzarovski (2018) argues that the available methods for gauging energy poverty are threefold, direct measurement of the level of energy services, measurement via energy expenditure, and a subjective approach, adding that the first approach is rare and never attempted on a nationwide scale, even in European countries. ${ }^{7}$ This study develops a new energy poverty measure that belongs to the first category.

This proposed measure is a kind of multidimensional energy poverty index (MEPI), developed by Okushima (2017). ${ }^{8}$ The MEPI is an application of multidimensional poverty measurement in the Alkire and Foster (2011)'s fashion to measuring energy poverty in developed countries. In the MEPI approach, consider a population with $n$ households $(i=1, \cdots, n)$ and $d \geq 2$ dimensions (attributes) of energy poverty $(j=1, \cdots, d)$; then, the achievement of household $i$ in dimension $j$ can be denoted by $y_{i j}$. Notably, the achievement can be defined in the case of ordinal or categorical type of data, by separating “deprived” from "not-deprived” in the dimension.

Here, this study sets two dimensions (attributes) featuring energy poverty in Japan: usage of energy services in calorific value (including space heating and cooling, water heating, lighting, cooking and appliance usage, but excluding mobility), and income. The former represents the fulfillment of domestic energy needs or well-being of households. The latter, the income dimension, implies affordability. The income dimension plays an important role in avoiding misidentification

\footnotetext{
${ }^{7}$ Examples of direct measurement are limited. Indoor temperatures are examined by Healy and Clinch (2002) for 1500 Irish households, by Oreszczyn et al. (2006) for 1604 households in 5 urban areas of England, and by Santamouris et al. (2007) for 1110 households in the Athens area.

8 The multidimensional energy poverty index used in Okushima (2017) sets three dimensions energy costs, income, and energy efficiency of housing. Unlike the new measure in this study, it belongs to expenditure-based measures, not using the concept of "type."
} 
(false positive) of wealthy households as energy poor, just because of their low use of energy services, partly due to their preferences or choices - a strong preference for an eco-friendly lifestyle, for example. ${ }^{9}$

The multidimensional approach in this study considers energy poverty as the intersection of two dimensional-poverty (Okushima, 2017). Each dimensional-poverty can be defined as the shortfall from the threshold (poverty line) for that dimension (attribute), i.e., energy use or income. When $z_{j}$ denotes the threshold of dimension $j$, one could define the dimension $j$ 's specific poverty of household $i$ if $y_{i j}<z_{j}$.

To measure the dimensional-poverty of energy use, this study introduces a new concept that of "type." ${ }^{10}$ For the analysis, the whole population is divided into "types." Each type consists of households with the same or similar circumstances; the circumstances are here characterized by components such as the climate where the household lives, family structure, and dwelling type. This study divides households into 16 types $(t=1, \cdots, 16)$. Each type consists of households with similar circumstances - spatial, socio-demographic, and dwelling-type. These are the three pivotal components that affect household energy needs (Table 2). Section 4 discusses the appropriateness of this typology.

To sum up, the definition of (multidimensional) energy poverty in this study is as follows:

$$
\text { Household } i \text { is energy poor } q \Leftrightarrow y_{i 1}<z_{t(i) 1} \& y_{i 2}<z_{2} \text {, }
$$

where $t_{(i)}$ is the type that household $i$ belongs to. As the formula indicates, this approach sets multiple thresholds (poverty lines) for type $t$ in dimension 1 (energy use). For the energy use dimension, the threshold of type $t$ is $60 \%$ of the median energy consumption of type- $t$ households. The $60 \%$ median threshold follows the standard procedure of measuring (relative) income poverty in the EU and other countries. ${ }^{11}$ Moreover, to correct for economies of scale for household size, the energy consumption of

\footnotetext{
${ }^{9}$ On this point, a famous example of "fasting" by Amartya Sen serves as a good reference. Sen (1992, p. 52) argues that “'fasting' as a functioning is not just starving; it is choosing to starve when one does have other options. In examining a starving person's achieved well-being, it is of direct interest to know whether he is fasting or simply does not have the means to get enough food." In this context, the underconsumption of energy corresponds to "starving," where an "eco-friendly lifestyle" does the "fasting."

${ }^{10}$ The concept of "type" is attributed to Roemer $(1993,1998)$. He develops the concept in the context of "equality of opportunity."

${ }^{11}$ Energy or fuel poverty is traditionally understood as a relative poverty concept rather than an absolute one (Liddell et al., 2012). The 50\% median threshold is also popular for measuring income poverty. However, the $60 \%$ median threshold is more suitable for energy consumption because energy is a necessity and energy consumption increases at a slower pace than income.
} 
each household is equivalized with the square root scale; energy consumption of each household is divided by the square root of household size. ${ }^{12}$

For dimension 2 (income), previous studies consider households in the lowest 30\% income group as (dimensionally) poor (Boardman, 1991; Okushima, 2017). This study employs this definition, although the dataset includes only range-type information on annual income. Hence, the income threshold $z_{2}$ is defined as 5 million yen (the income ranges 1 and 2 in Table 3 correspond to “dimensionally poor”). This is reasonable because the $30^{\text {th }}$ percentile of annual (before-tax) income of Japanese households is 3.04 million yen, according to the 2014 National Survey of Family Income and Expenditure, a representative governmental survey of more than 50,000 respondents.

The above steps can fully identify whether household $i$ belongs to the energy-poor group $(q)$. After the "identification” step, i.e., who are the poor?, the other step is "aggregation” (Sen, 1976, 1979). This study uses a simple headcount ratio, $H$, for aggregation. $H$, the ratio of the "poor" $(q)$ to the total population $(n)$, represents the extent of poverty in society:

$$
H=q / n \text {. }
$$

The headcount ratio, categorized as one of the Foster-Greer-Thorbecke (FGT) measures, is widely used as a general income poverty measure (Foster et al., 1984). $H$ is the measure used in this study.

In this study, this new measure is applied to the Japanese case with unique microdata of Japanese households' energy use. The dataset was constructed for my own work based on anonymized information in "A Nationwide Pilot Survey, Survey on the Actual Conditions of Households for the Estimation of Carbon Dioxide Emissions,” conducted by the Ministry of Environment (MOE), Japan. ${ }^{13}$ The survey was conducted by the MOE from October in 2014 to September in 2015 to explore energy consumption, $\mathrm{CO}_{2}$ emissions, energy expenditure, and other characteristics (income, dwelling type, energy saving behavior, etc.), with a sample of about 6,000 households from all over Japan. For reference, Table 1 shows the sample size for each region and prefecture. In the survey, each household was assigned a sampling weight designed to replicate the whole population of Japan. These weights are used in all calculations to obtain unbiased estimates. Using this unique dataset, this study first investigates regional energy poverty in Japan via a direct measurement approach. Table 3 shows the descriptive statistics for the items used in this study.

\footnotetext{
${ }^{12}$ For equivalence scales, see, for example, “What are equivalence scales?” by OECD (www.oecd.org/eco/growth/OECD-Note-EquivalenceScales.pdf).

13 The details of this survey are provided by the Ministry of Environment, Japan (http://www.env.go.jp/earth/ondanka/ghg/kateitokei.html, in Japanese).
} 


\section{Results}

This section analyzes the regional characteristics of energy poverty in Japan using the new approach and unique data. In the run-up to the evaluation of energy poverty, Fig. 3 shows the distribution of household energy use in calorific value for the 10 regions of Japan (see also Table 1\&Fig. 2). As explained, Japan has a very diverse climate, i.e., from subarctic to subtropical zones. The figure shows that energy consumption in Japan varies greatly between regions, i.e., from the highest in Hokkaido, which is the northernmost region, to the lowest in Okinawa, the southernmost region. The results in this figure clearly imply that evaluating energy poverty with little regard to such divergent energy needs between regions might result in serious misidentification.

Fig. 4 indicates the (average) energy use in joules by energy source in the 10 regions. Notably, the contribution of kerosene (heating oil) in calories is quite large in Japan, mainly for heating in winter. In the northern part of Japan, including Hokkaido, Tohoku, and Hokuriku, which have much colder climates with heavy snow, the residents highly rely on winter heating with kerosene. On the other hand, in the southern part of Japan (e.g., Okinawa), there is less or even no need for heating in winter. Fig. 4 reflects these situations.

As explained in Section 3, this study applies a new measure to examine regional energy poverty in Japan, fully considering differences in spatial, socio-demographic and built-environmental vulnerability factors. Table 2 defines 16 types of Japanese households for this analysis; each of these 16 types has a corresponding poverty threshold in the energy use dimension. This typology reflects the three pivotal factors contributing to the energy need differences in Japan: the climatic factor, the socio-demographic factor, and the built-environment (dwelling type) factor (see also Bouzarovski and Simcock, 2017).

Noteworthy, to define the types, the analysis aggregates the 10 Japanese regions into 4, in line with the similarity of climate and energy use patterns (see Fig. 2\&3). This ensures a sufficient sample size for each type. This categorization might require further discussion because of the wide variety of climatic conditions that affect the energy needs of residents, even in the same region. For instance, it is known that energy poverty rates become higher along with the altitude (Papada and Kaliampakos, 2016). Therefore, the more types we define, the more exact would be the identification of energy need differences. On the other side, finer partitioning inevitably yields fewer observations in each type. The resolution adequacy wholly depends on the dataset, adding to the research objective. Unfortunately, if the original 10 regions are applied, there become 40 types in total. The sample size then becomes insufficient for some types to be analyzed (see also Table 1).

Consequently, this study divides households into 4 types in terms of region, considering 16 types in total as an adequate number to capture energy need differences with a reasonable level of accuracy and secure a sufficient number of observations for each type. Table 4 clearly shows the difference in mean and median energy uses between types, which demonstrates that this classification 
is appropriate. Concerning the climatic factor, the table and Fig. 3 confirm that this classification reflects the differences in energy needs reasonably well.

On the socio-demographic aspect, this analysis divides households into the "vulnerable type" and others. Households with elderly (65 years of age or over) member(s) are defined as vulnerable households. ${ }^{14}$ Table 4 clearly shows the differences in energy use between vulnerable and non-vulnerable households in each region. Okushima $(2016,2017)$ also shows that elderly households are especially vulnerable to energy poverty in the Japanese context. Furthermore, other evaluations of energy poverty via direct measurement (of indoor temperature) show, inter alia, that households with elderly members have higher energy needs, especially for space heating (Healy and Clinch, 2002; Oreszczyn et al., 2006). ${ }^{15}$

Moreover, on the dwelling type, the analysis partitions households into two types according to whether they live in apartment-type or detached-type houses. This is the most significant built characteristic that affects household energy consumption in Japan. ${ }^{16}$ Table 4 shows large differences in energy use between detached houses and apartments, supporting the suitability of this typology.

This study now provides the results of regional energy poverty in Japan, measured by the new approach. Table 5 shows the energy poverty rates for the 10 regions, as well as for the entire country. The result shows $7.5 \%$ of households in Japan are energy poor, which is similar to previous estimates by Okushima (2016, 2017), although the measurement approaches are different. However, the regional rates show large variations; in particular, the Shikoku and Kyushu regions experience relatively high rates of energy poverty. The lower income and larger share of the off-gas-grid population in these areas are the main reasons for this result. In addition, the (energy-poor) people in these areas have a choice of limiting energy use for heating in winter due to the warmer climate. On the contrary, the northernmost region of Hokkaido, belonging to the subarctic zone, faces extreme cold climate in winter, providing little room to limit energy use for heating, even for low-income households confronting high energy prices. Hence, the energy poverty rate is unexpectedly low in Hokkaido through the direct measurement approach.

${ }^{14}$ Here, the term of "vulnerable households" denotes the household types that are at high risk of energy poverty. A different definition can categorize households with elderly person(s), young child(ren), or person(s) with disability or long-term illness as "vulnerable households" (Boardman, 2010; Hills, 2012). However, the dataset has no information on disabled persons; furthermore, a large segment of households would be categorized as vulnerable if including those with child(ren), as Boardman (2010) notes. To double-check, this study tries another definition, which categorizes households with elderly member(s) or child(ren) as vulnerable. However, the outcome shows that the original definition works better.

15 Notably, the expected result is not obtained for the apartment types in Okinawa (Type 15 vs. Type16). This is mainly because there is little need for winter heating in Okinawa, which is a subtropical area of Japan, and old apartments normally have no bathtubs to warm up in Okinawa. These special features probably account for the difference from other areas.

${ }^{16}$ In other countries, energy poverty frequently manifests in detached houses rather than apartments. Santamouris et al. (2007) empirically show that detached houses consume 50\% more energy for heating per square meter than do apartments. 
Interestingly, the table also presents counterfactual energy poverty rates with a uniform threshold nationwide for the energy use dimension. The results clearly show that this study's multiple thresholds approach is suitable for capturing regional differences in energy needs accurately. The hypothetical result with a nationwide uniform threshold shows exceptionally low rates of energy poverty in the northern part of Japan, such as Hokkaido (2.9\%). This is because the $60 \%$ national median threshold of energy use, in calorific value, is easily exceeded with the high need for energy for heating in those areas. On the contrary, Okinawa, in the subtropical area of Japan, is distinguished by the fact that heating in winter is scarcely needed, surely causing the extraordinarily high poverty rate of 39.0\% with the national uniform threshold. This counterfactual result implies that using the national uniform threshold necessarily produces an inappropriate estimation in the direct measurement of energy service usage, which leads to a misinterpretation of the current picture and wrong policy implications on energy poverty. Moreover, the results and implications are thoroughly incompatible from the perspective of energy or spatial justice, especially for false negatives such as in the northern regions (Liddell et al., 2012; Bouzarovski and Simcock, 2017). ${ }^{17}$

Table 6 describes the effects of changes in energy poverty rates if some energy source (electricity, gas, or kerosene) is excluded. The effects here refer to the poverty reduction effects that each energy source possesses. In other words, the result provides information about energy sources that are important in preventing energy poverty in each region. Notably, the result shows that kerosene holds the key to overcoming energy poverty in the northern part of Japan, especially in the Hokkaido and Tohoku regions. In cold climate areas, kerosene is indispensable in securing warmth for residents in winter. However, the results show large differences in the poverty reduction effects of energy sources between regions. In particular, the effect of kerosene use accounts for merely $2.4 \%$ in Okinawa, in the southern region of Japan, because of its minimal energy needs for winter heating. These results bring up an important point on the energy or spatial justice issue mentioned earlier, as well as on the low-carbon energy transition in Japan in the future: How should kerosene be treated afterward? In Japan, kerosene plays an important role as a relatively cheap energy source for heating, high in calorie but relatively high in carbon intensity too. As the results show, Japan now faces a trade-off between energy poverty alleviation and climate change mitigation. High carbon pricing without any alleviation measures might worsen the situation of energy-poor households, especially those living in cold-climate areas. It is necessary to discuss the positive and negative effects of carbon

${ }^{17}$ Reasonably, the climate is a circumstance beyond one's control or responsibility. Furthermore, Bouzarovski and Simcock (2017, p.645) argue that "spatial differences in energy poverty and vulnerability are not the responsibility of variations in individual 'choices', but instead predominantly result from structural geographical inequities that are engrained in various stages of energy systems, and, moreover, in the fundamental infrastructural, economic, and cultural make-up of societies.” 
pricing on each region, as well as those of the feed-in tariffs (FIT), in the context of the proposed low-carbon energy transition in Japan. ${ }^{18}$

Fig. 5 presents another perspective on energy justice, namely, the unit cost (or unit price) of energy on a calorific basis (Japanese yen / mega joule) for the energy-poor and other households. The result indicates that the unit cost of energy for all energy services is much higher for the energy-poor than it is for non-energy-poor households (the difference is significant at the 0.001 level by the $t$-test). It clearly suggests the presence of an "energy poverty premium” in Japan. ${ }^{19}$ The concept of poverty premium states that the poor pay more for essential goods and services (Caplovitz, 1963; Davies et al., 2016). Evidently, this energy poverty premium, per amount of heat, aggravates the seriousness of energy poverty due to higher prices of energy services for the energy poor. This disparity in the price of energy services between the poor and non-poor is definitely an injustice (Boardman, 2010). It can be attributed to, for example, the differences in energy infrastructures (e.g., on or off the gas grid; see Roberts et al., 2015; Bouzarovski and Simcock, 2017), transport costs, and market competitiveness across regions. However, it is too complex a subject to be analyzed here in detail, and surely needs research that is more rigorous. ${ }^{20}$

\section{Concluding remarks and policy implications}

This study develops a new approach to measuring energy poverty in calorific value directly, and evaluates regional energy poverty in Japan. Thus far, little was known about regional energy poverty in Japan, despite previous studies such as Okushima (2016, 2017), which evaluate energy poverty in Japan using national-level estimates. The result of this study provides several new insights into the scholarship in this field. It illustrates large variation in energy poverty between regions, and notably, adding to northern regions such as Tohoku, the southern regions of Shikoku and Kyushu experience higher energy poverty. The result also highlights the important role of kerosene in ensuring adequate energy services, especially in the northern part of Japan. As a noticeable phenomenon in terms of energy justice, the analysis indicates the existence of an "energy poverty premium" in Japan on the unit cost of energy (per amount of heat). These facts can be confirmed only after the novel approach is used to conduct an energy poverty analysis of energy services usage.

In the context of energy policy in Japan after the Fukushima nuclear accident, one expects higher carbon pricing and further electrification through renewable energy promotion in the years to

${ }^{18}$ Chapman and Okushima (2018) suggest that the current low-carbon energy transition policies, such as FIT, in Japan are exacerbating energy poverty.

${ }_{19}$ The fact that an "energy poverty premium" exists in each of the 10 regions is also verified.

${ }^{20}$ As similar examples of the poverty premium, Reames et al. (2018) indicate the price disparity of energy-efficient bulbs between high-poverty and wealthier areas in an urban U.S. county, and Walker et al. (2015) illustrate the spatial disparities in the price of residential heating oil in Northern Ireland, which have huge impacts on energy poverty. 
come. The Japanese government has proactively attempted to reduce fossil fuel use after the 2015 Paris Agreement. However, as many studies indicate, there is a trade-off between climate change mitigation and energy poverty alleviation (e.g., Ürge-Vorsatz and Tirado Herrero, 2012; Bouzarovski, 2018). The result of this study suggests that policies such as carbon taxes would raise the prices of fossil fuels and, without alleviation measures, would have serious consequences for the energy poor - especially through high-priced kerosene. The result also reveals that the energy poor are even now facing higher prices of energy, per amount of heat, than the non-poor — the phenomenon of "energy poverty premium” in Japan.

This study confirms the prevalence of energy poverty throughout the Japanese regions. Nevertheless, in Japan, energy poverty is not recognized as an independent issue distinct from income poverty. Hence, there is no policy agenda in Japan to address energy poverty, only having traditional types of policies such as income support for low-income households or promoting energy efficiency of housing. Such existing policies do not seem very effective for energy poverty alleviation, increasing the need for specialized measures against energy poverty (Chapman and Okushima, 2018). Furthermore, the current low-carbon transition policies in Japan such as FIT generally exacerbate energy poverty. The energy poor few gain the benefits of current transition policies, only bearing the burden, then having negative attitude toward the transition (Chapman and Okushima, 2018). The energy transition in Japan needs to be more progressively promoted, with full consideration of disadvantaged populations such as the energy poor, from the standpoint of energy justice or just transition (McCauley and Heffron, 2018). ${ }^{21}$ Solar power is playing a major role in the context of Japanese energy transition, and access to solar power is of decisive importance in dealing effectively with the low-carbon transition from fossil fuels (METI, 2017). Hence, the government needs to help the energy poor to gain the benefits of solar power by subsidizing their own deployment or the community-based deployment of solar panels. ${ }^{22}$ Moreover, the promotion of housing energy efficiency, especially for energy-poor households in cold climate regions, is also an urgent need. This is also a no-trade-off policy between energy poverty amelioration and $\mathrm{CO}_{2}$ emissions reduction. ${ }^{23}$

On the issue of measurement, this study presents a new approach to measuring energy poverty, especially for developed nations. This (multidimensional) energy poverty measure has two features that existing measures do not possess. First, it evaluates energy poverty via the direct

\footnotetext{
${ }^{21}$ Adam Smith considers a similar case in the restoration of free trade. He said, "[The equitable regard] requires that changes of this kind should never be introduced suddenly, but slowly, gradually, and after a very long warning” (Smith, 1976, IV. ii .44).

${ }^{22}$ Although there is no actual example, Power Producers and Suppliers (PPS) established by local governments can distribute cheaper energy, e.g., generated from community solar, to the energy poor after the full liberalization of the retail electricity market in Japan in 2016.

${ }^{23}$ As an advanced case in Japan, Shimokawa town, a small inland town in Hokkaido, provides public housing with a district heat supply system of locally produced woody biomass for low-income households.
} 
measurement of energy use in calorific value, enabling us to gauge the underconsumption of energy services. In other words, this measure can evaluate directly whether a household is unable "to attain a socially and materially necessitated level of domestic energy services” (Bouzarovski and Petrova, 2015). Second, the method can consider the difference in energy needs attributable to circumstances such as climatic, socio-demographic, and built-environmental factors, which are directly linked to energy or spatial justice issues. The method introduces a new concept of "type," as well as the multiple thresholds approach according to such types, which enables us to properly assess regional energy poverty, controlling the difference in household energy needs. This study then clearly shows the advantages of this multiple thresholds approach for regional energy poverty assessment. In Japan, evaluating regional energy poverty with a nationwide uniform threshold is inappropriate because it causes misidentification of poverty.

The concept of "type" or the multiple thresholds approach is applicable to even expenditure-based measures such as the $10 \%$ indicator. The uniform threshold is possibly problematic even if expenditure-based measures are used. Therefore, it is better to reconsider whether the national uniform threshold (poverty line) is appropriate even in the case of expenditure-based measures from the perspective of energy or spatial justice (Liddell et al., 2012; Romero et al., 2018).

Future research is necessary, specifically on the following issues. First, the typology used in this study is debatable. Ultimately, circumstances differ for each household; aggregating and averaging over types inevitably always masks any differences within a type (Middlemiss and Gillard, 2015; Bouzarovski and Simcock, 2017). Nevertheless, some level of grouping is indispensable for poverty measurement, and the fineness of grouping wholly depends on the research purpose and the dataset.

Furthermore, this study focuses on the regional or climatic difference aspect, and the typology for the socio-demographic or dwelling aspect remains insufficient because it is necessary to ensure adequate sample sizes for all types. ${ }^{24}$ Nevertheless, there is room for argument on these points, e.g., regarding the energy efficiency of housing. On the dwelling type, this study only splits housing into detached- and apartment-types, whilst the typology for dwelling vulnerability may not be sufficient given the disparities of energy efficiency or quality of housing prevailing in Japan. The same holds true for the partitioning of socio-demographic factors.

Finally, on the possibility of application, this new method may not be so effective if applied to a more heterogeneous country with a great variety of behavioral culture in energy use. For example, even in Japan, bathing culture differs among regions, highlighting the needs for future research.

The study explains the regional characteristics of energy poverty in Japan for the first time, using a new direct measurement approach. The analysis sheds light on previously unexplained issues, such as the essential role of kerosene in the northern regions and the existence of an energy poverty

${ }^{24}$ Another problem is that too much segmentation might generate a type where most constituent members should be identified as poor. Even in that case, according to this approach, members above the $60 \%$ median in the type are identified as non-poor, which is problematic. 
premium in Japan, which are very intriguing from the perspective of energy or spatial justice. These findings are identified only through the application of the new method - evaluating energy poverty via direct measurement of energy service usage of households. The author hopes this new approach and its findings will contribute to the scholarship in this field.

\section{Acknowledgments}

The author would like to thank his colleagues and students for their assistance with this research. Furthermore, the author wishes to thank the editors and anonymous referees of this journal. This research was supported by the Grant-in-Aid for Scientific Research (JSPSKAKENHI, Grant No.17K00679).

Declarations of interest: none

\section{References}

Alkire, S., and Foster, J., “Counting and multidimensional poverty measurement,” Journal of Public Economics, 95, pp. 476-487, 2011.

Alkire, S., Foster, J., Seth, S., Santos, M.E., Roche, J.M., and Ballón, P., Multidimensional Poverty Measurement and Analysis. Oxford University Press; Oxford, 2015.

Aristondo, O., and Onaindia, E., “Counting energy poverty in Spain between 2004 and 2015,” Energy Policy, 113, pp. 420-429, 2018.

Boardman, B., Fuel Poverty: From Cold Homes to Affordable Warmth. Belhaven Press; London, 1991.

Boardman, B., Fixing Fuel Poverty: Challenges and Solutions. Earthscan; London, 2010.

Bouzarovski, S., Energy Poverty: (Dis)Assembling Europe’s Infrastructural Divide. Palgrave Macmilan; Switzerland, 2018.

Bouzarovski, S., and Petrova, S., “A Global perspective on domestic energy deprivation: overcoming the energy poverty-fuel poverty binary,” Energy Research and Social Science, 10, pp. 31-40, 2015.

Bouzarovski, S., and Simcock, N., “Spatializing energy justice,” Energy Policy, 107, pp. 640-648, 2017.

Brunner, K.-M., Spitzer, M., and Christanell, A., "Experiencing fuel poverty. Coping strategies of low-income households in Vienna/Austria,” Energy Policy, 49, pp. 53-59, 2012.

Caplovitz, D., The Poor Pay More: Consumer Practices of Low-Income Families. Free Press of Glencoe; New York, 1963.

Chapman, A., and Okushima, S., "Engendering an inclusive low-carbon energy transition in Japan: considering the perspectives and awareness of the energy poor,” USAEE Working Paper, No. 18-372, 2018. 
Davies, S., Finney, A., and Hartfree, Y., Paying to be poor: uncovering the scale and nature of the poverty premium. The University of Bristol’s Personal Finance Research Centre, 2016.

Day, R., Walker, G., and Simcock, N., “Conceptualising energy use and energy poverty using a capabilities framework,” Energy Policy, 93, pp. 255-264, 2016.

Fabbri, K., "Building and fuel poverty, an index to measure fuel poverty: an Italian case study,” Energy, 89, pp. 244-258, 2015.

Fizaine, F., and Kahouli, S., "On the power of indicators: how the choice of fuel poverty indicator affects the identification of the target population,” Applied Economics, 51, pp. 1081-1110, 2019.

Foster, J., Greer, J., and Thorbecke, E., “A class of decomposable poverty measures,” Econometrica, 52, pp. 761-766, 1984.

González-Eguino, M., “Energy poverty: an overview,” Renewable and Sustainable Energy Reviews, 47, pp. 377-385, 2015.

Healy, J.D., and Clinch, J.P., "Fuel poverty, thermal comfort and occupancy: results of a national household-survey in Ireland,” Applied Energy, 73, pp. 329-343, 2002.

Heindl, P., "Measuring fuel poverty: general considerations and application to German household data," FinanzArchiv, 71, pp. 178-215, 2015.

Hills, J., Getting the Measure of Fuel Poverty. Department of Energy and Climate Change, Government of UK; London, 2012.

Howden-Chapman, P., Viggers, H., Chapman, R., O’Sullivan, K., Telfar Barnard, L., and Lloyd, B., "Tackling cold housing and fuel poverty in New Zealand: a review of policies, research, and health impacts,” Energy Policy, 49, pp. 134-142, 2012.

IEA (International Energy Agency), Energy Poverty: How to Make Modern Energy Access Universal? OECD/IEA; Paris, 2010.

Imbert, I., Nogues, P., and Sevenet, M., "Same but different: on the applicability of fuel poverty indicators across countries-insights from France,” Energy Research and Social Science, 15, pp. 75-85, 2016.

Jenkins, K., McCauley, D., Heffron, R., Stephan, H., and Rehner, R., “Energy justice: a conceptual review,” Energy Research and Social. Science, 11, pp. 174-182, 2016.

Jones, B.R., Sovacool, B., and Sidortsov, R.V., "Making the ethical and philosophical case for 'energy justice'," Environmental Ethics, 37, pp. 145-168, 2015.

Legendre, B., and Ricci, O., "Measuring fuel poverty in France: which households are the most fuel vulnerable?” Energy Econonomics, 49, pp. 620-628, 2015.

Liddell, C., Morris, C., McKenzie, S.J.P., and Rae, G., "Measuring and monitoring fuel poverty in the UK: national and regional perspectives,” Energy Policy, 49, pp. 27-32, 2012.

März, S., “Assessing the fuel poverty vulnerability of urban neighbourhoods using a spatial multi-criteria decision analysis for the German city of Oberhausen,” Renewable and Sustainable Energy Reviews, 82, pp. 1701-1711, 2018. 
McCauley, D., Heffron, R., “Just transition: Integrating climate, energy and environmental justice,” Energy Policy, 119, pp. 1-7, 2018.

METI (Ministry of Economy, Trade and Industry), Energy White Paper 2017. Ministry of Economy, Trade and Industry, Government of Japan, 2017.

Middlemiss, L., and Gillard, R., "Fuel poverty from the bottom-up: characterising household energy vulnerability through the lived experience of the fuel poor,” Energy Research and Social Sciences, 6, pp. 146-154, 2015.

Moore, R., “Definitions of fuel poverty: implications for policy,” Energy Policy, 49, pp. 19-26, 2012.

Okushima, S., “Measuring energy poverty in Japan, 2004-2013,” Energy Policy, 98, pp. 557-564, 2016.

Okushima, S., “Gauging energy poverty: a multidimensional approach,” Energy, 137, pp. 1159-1166, 2017.

Oreszczyn, T., Hong, S.H., Ridley, I., Wilkinson, P., and The Warm Front Study Group, “Determinants of winter indoor temperatures in low income households in England,” Energy and Buildings, 38, pp. 245-252, 2006.

O’Sullivan, K.C., Howden-Chapman, P.L., and Fougere, G.M., "Fuel poverty, policy, and equity in New Zealand: the promise of prepayment metering,” Energy Research and Social Science, 7, pp. 99-107, 2015.

Papada, L. and Kaliampakos, D., “Measuring energy poverty in Greece,” Energy Policy, 94, pp. 157-165, 2016.

Poruschi, L., and Ambrey, C.L., "Densification, what does it mean for fuel poverty and energy justice? An empirical analysis,” Energy Policy, 117, pp. 208-217, 2018.

Reames, T.G., Reiner, M.A. and Stacey, M.B., “An incandescent truth: disparities in energy-efficient lighting availability and prices in an urban U.S. county,” Applied Energy, 218, pp. 95-103, 2018.

Roberts, D., Vera-Toscano, E., and Phimister, E., “Fuel poverty in the UK: is there a difference between rural and urban areas?” Energy Policy, 87, pp. 216-223, 2015.

Robinson, C., Bouzarovski, S., and Lindley, S. “'Getting the measure of fuel poverty’: the geography of fuel poverty indicators in England,” Energy Research and Social Sciences, 36, pp. 79-83, 2018a.

Robinson, C., Bouzarovski, S., and Lindley, S. “Multiple vulnerabilities? Interrogating the spatial distribution of energy poverty measures in England,” in N. Simcock, H. Thomson, S. Petrova, and S. Bouzarovski (eds.), Energy Poverty and Vulnerability: A Global Perspective. Routledge; UK, pp. 141-168, 2018b.

Roemer, J.E., “A Pragmatic Theory of responsibility for the egalitarian planner,” Philosophy and Public Affairs, 22(2), pp. 146-166, 1993.

Roemer, J.E., Equality of Opportunity. Harvard University Press; Cambridge, MA, 1998.

Romero, J.C., Linares, P., and López, X., “The policy implications of energy poverty indicators,” Energy Policy, 115, pp. 98-108, 2018. 
Santamouris, M., Kapsis, K., Korres, D., Livada, I., Pavlou, C., and Assimakopoulos, M.N., “On the relation between the energy and social characteristics of the residential sector, " Energy and Buildings, 39, pp. 893-905, 2007.

Santamouris, M., Paravantis, J.A., Founda, D., Kolokotsa, D., Michalakakou, P., Papadopoulos, A.M., Kontoulis, N., Tzavali, A., Stigka, E.K., Ioannidis, Z., Mehilli, A., Matthiessen, A, and Servou, E., "Financial crisis and energy consumption: a household survey in Greece,” Energy and Buildings, 65, pp. 477-487, 2013.

Sen, A., "Poverty: an ordinal approach to measurement,” Econometrica, 44(2), pp. 219-231, 1976.

Sen, A., "Issues in the measurement of poverty," Scandinavian Journal of Economics, 81(2), pp. 285-307, 1979.

Sen, A., Commodities and Capabilities. North-Holland; Amsterdam, 1985.

Sen, A., Inequality Reexamined. Harvard University Press; Cambridge, MA, 1992.

Smith, A., An Inquiry into the Nature and Causes of the Wealth of Nations. Oxford University Press; Oxford, 1789/1976.

Sovacool, B.K., "Fuel poverty, affordability, and energy justice in England: policy insights from the Warm Front Program,” Energy, 93, pp. 361-371, 2015.

Sovacool, B.K., Heffron, R.J., McCauley, D., and Goldthau, A., "Energy decisions reframed as justice and ethical concerns,” Nature Energy, 1, pp. 1-6, 2016.

Ürge-Vorsatz, D., and Tirado Herrero, S., "Building synergies between climate change mitigation and energy poverty alleviation,” Energy Policy, 49, pp. 83-90, 2012.

Walker, G., and Day, R., "Fuel poverty as injustice: integrating distribution, recognition and procedure in the struggle for affordable warmth,” Energy Policy, 49, pp. 69-75, 2012.

Walker, R., McKenzie, P., Liddell, C., and Morris, C., "Spatial analysis of residential fuel prices: local variations in the price of heating oil in Northern Ireland,” Applied Geography, 63, pp. 369-379, 2015.

Westrom, M., "Bathing in Japan: Applying a practice theory vocabulary to energy use through ethnography,” Energy Research and Social Sciences, 44, pp. 232-241, 2018.

Yenneti, K., Day, R., and Golubchikov, O., "Spatial justice and the land politics of renewables: dispossessing vulnerable communities through solar energy mega-projects,” Geoforum, 76, pp. 90-99, 2016. 


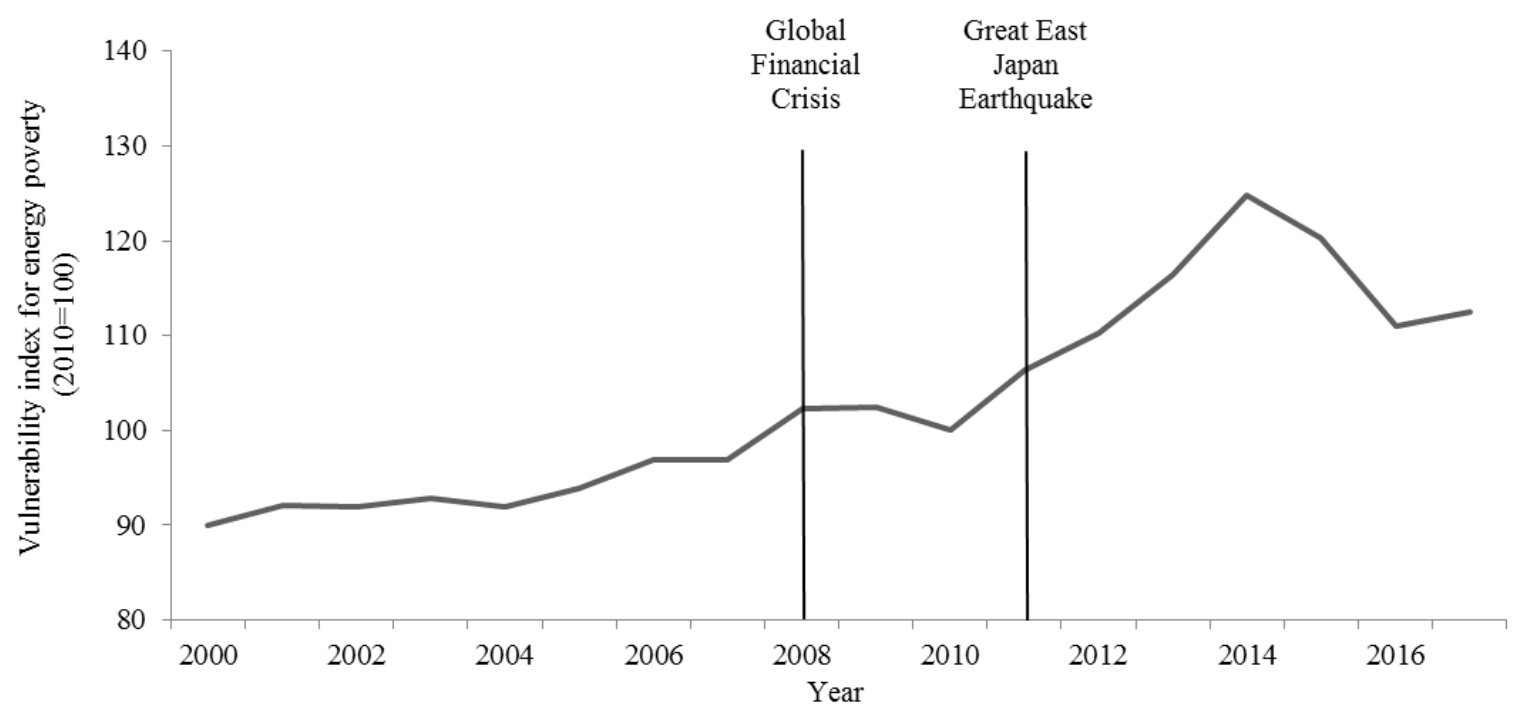

Fig. 1. Trends in the vulnerability index for energy poverty, 2000-2017

Note: The index is the ratio of energy CPI to household income. For more details on this index, see Okushima (2016).
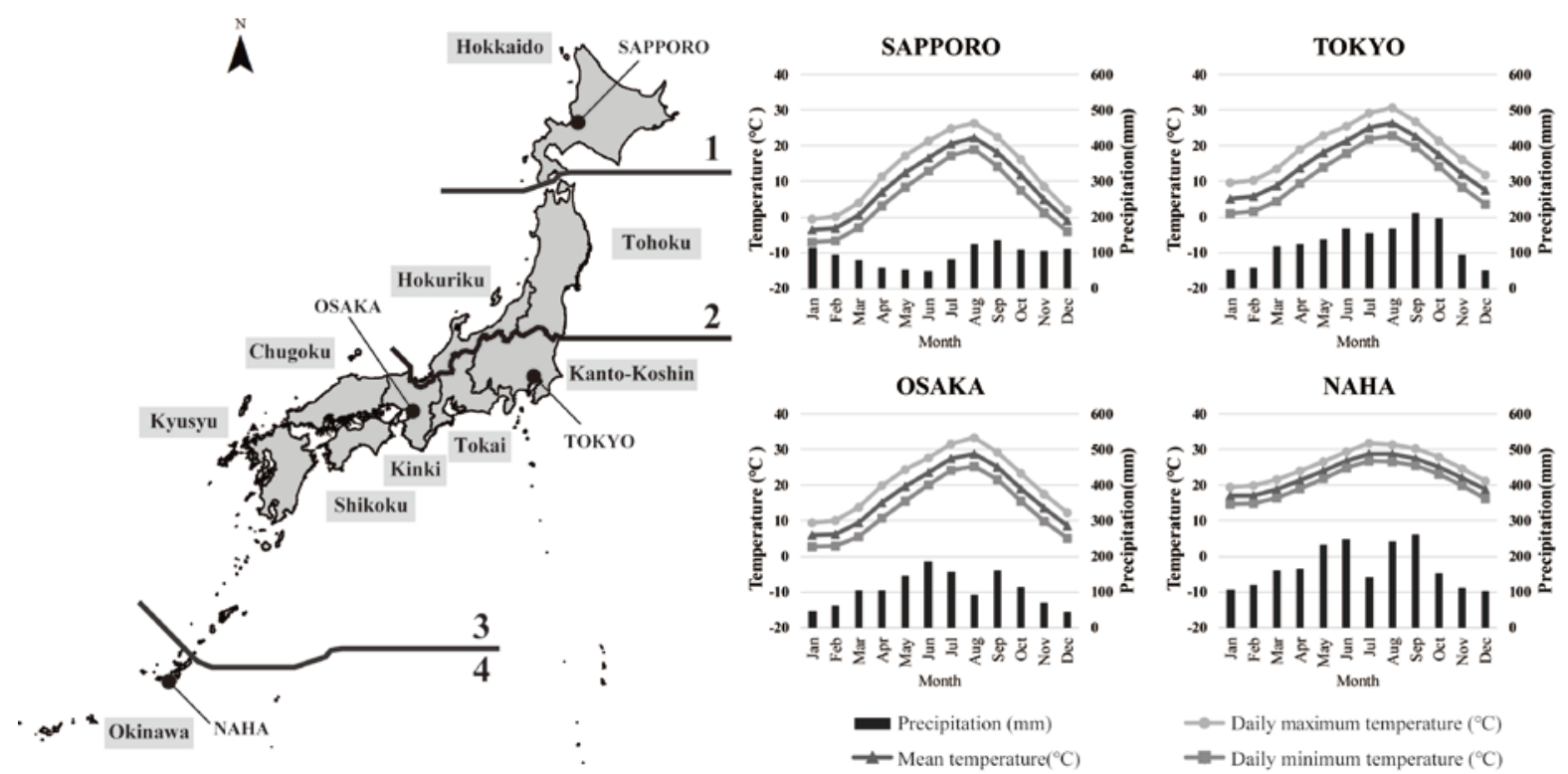

Fig. 2. Climate and regions of Japan

Note: Temperatures are monthly averages of daily mean, maximum, and minimum temperatures.

Precipitation is the amount of monthly precipitation.

Source: Tables of climatological normals (1981-2010), Japan Meteorological Agency (JMA).

http://www.data.jma.go.jp/obd/stats/data/en/index.html 


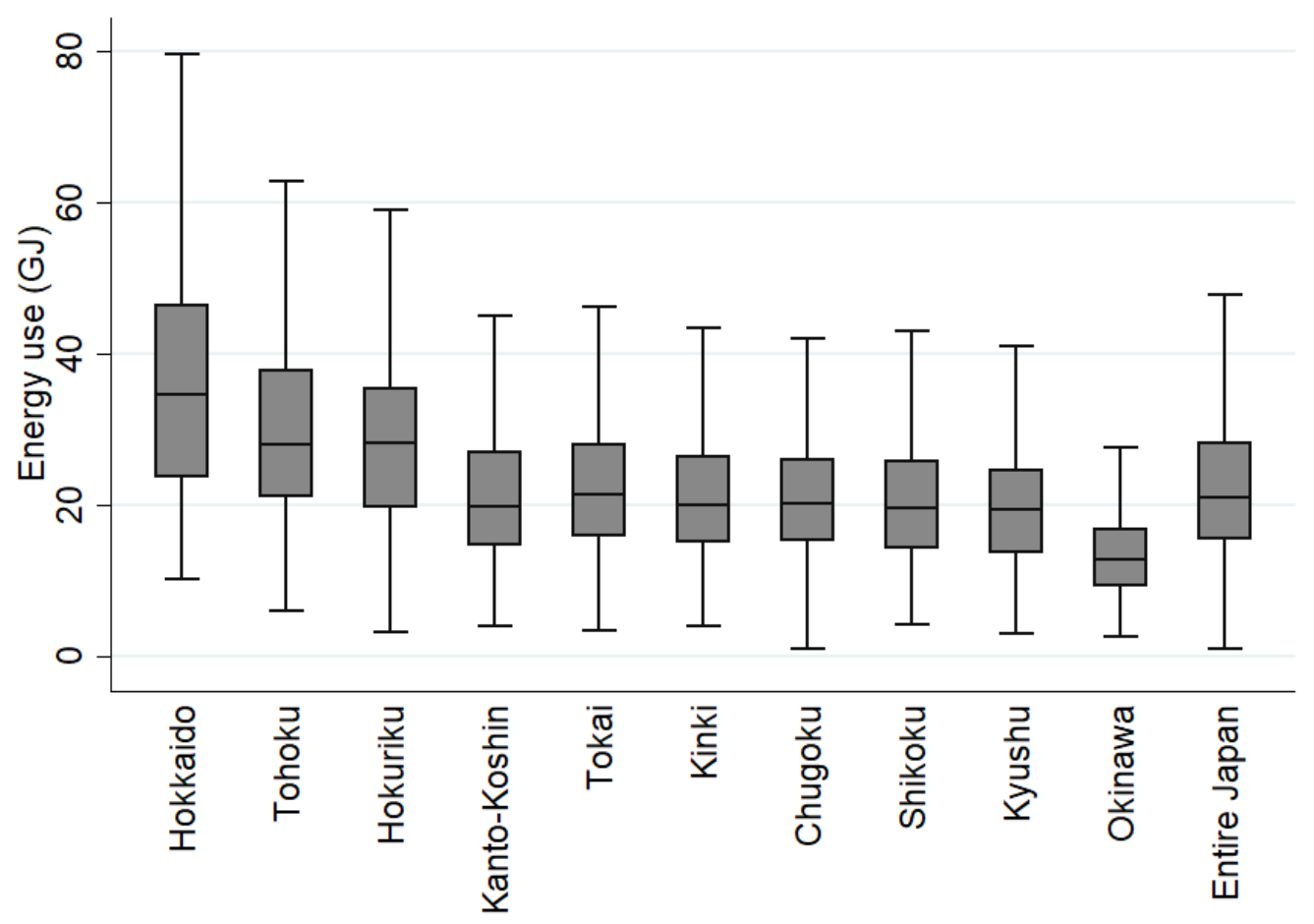

Fig. 3. Distribution of energy use in Japan and its 10 regions

Note: The horizontal line in each box is the median, the top and bottom of the box are upper and lower quartiles, and both ends of the whiskers are upper and lower adjacent values.

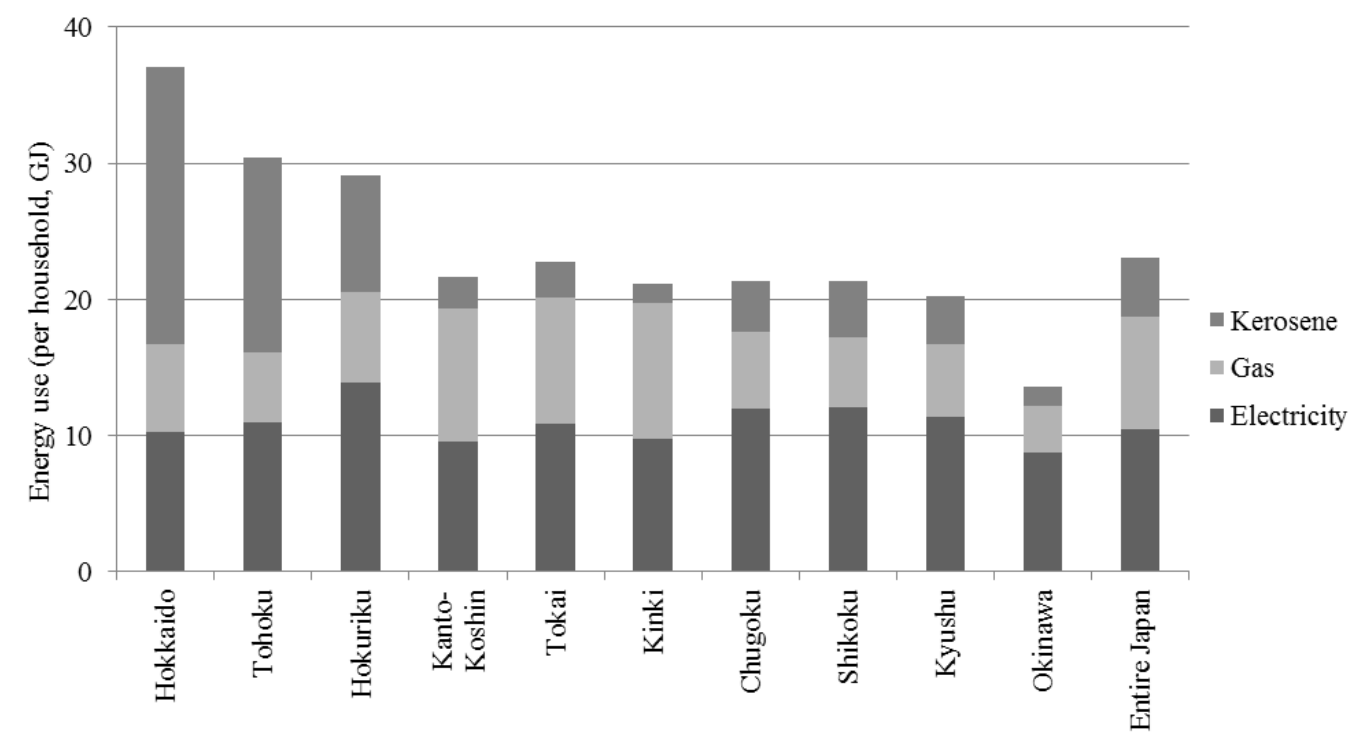

Fig. 4. Energy use by source in Japan and its 10 regions 


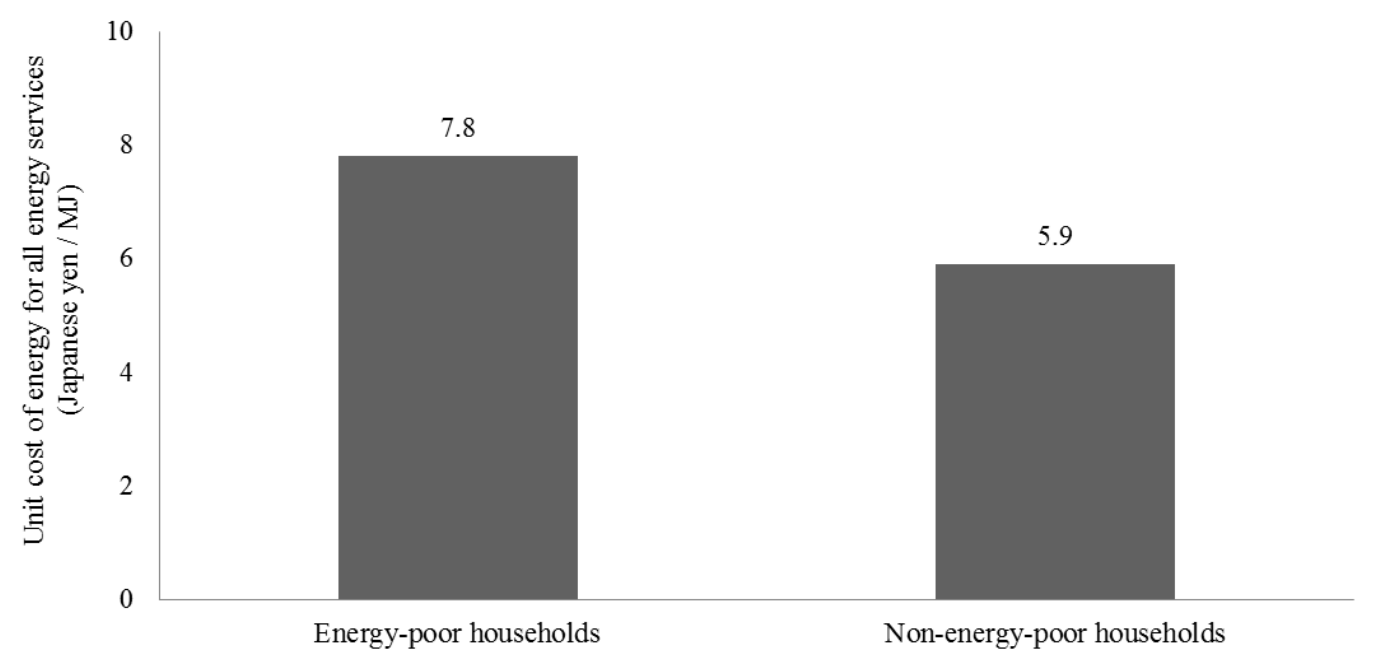

Fig. 5. Energy poverty premium in Japan

Note: The difference is significant at the 0.001 level by the $t$-test. 
Table 1. Detailed information on the Japanese regions and prefectures

\begin{tabular}{|c|c|c|c|c|c|}
\hline Region & Prefecture & $\begin{array}{r}\text { Area } \\
\left(\mathrm{km}^{2}\right)\end{array}$ & $\begin{array}{l}\text { Population } \\
\text { (thousand) }\end{array}$ & $\begin{array}{r}\text { Population density } \\
\left(\text { person/ } \mathrm{km}^{2} \text { ) }\right.\end{array}$ & Our sample size \\
\hline Hokkaido & Hokkaido & 83424 & 5382 & 65 & 519 \\
\hline \multirow{6}{*}{ Tohoku } & Aomori & 9646 & 1308 & 136 & 81 \\
\hline & Iwate & 15275 & 1280 & 84 & 82 \\
\hline & Miyagi & 7282 & 2334 & 320 & 153 \\
\hline & Akita & 11638 & 1023 & 88 & 96 \\
\hline & Yamagata & 9323 & 1124 & 121 & 65 \\
\hline & Fukushima & 13784 & 1914 & 139 & 107 \\
\hline \multirow{4}{*}{ Hokuriku } & Niigata & 12584 & 2304 & 183 & 163 \\
\hline & Toyama & 4248 & 1066 & 251 & 130 \\
\hline & Ishikawa & 4186 & 1154 & 276 & 134 \\
\hline & Fukui & 4190 & 787 & 188 & 90 \\
\hline \multirow{9}{*}{ Kanto-Koshin } & Ibaraki & 6097 & 2917 & 478 & 67 \\
\hline & Tochigi & 6408 & 1974 & 308 & 31 \\
\hline & Gunma & 6362 & 1973 & 310 & 29 \\
\hline & Saitama & 3798 & 7267 & 1913 & 150 \\
\hline & Chiba & 5158 & 6223 & 1206 & 146 \\
\hline & Tokyo & 2191 & 13515 & 6169 & 329 \\
\hline & Kanagawa & 2416 & 9126 & 3778 & 193 \\
\hline & Yamanashi & 4465 & 835 & 187 & 34 \\
\hline & Nagano & 13562 & 2099 & 155 & 34 \\
\hline \multirow{4}{*}{ Tokai } & Gifu & 10621 & 2032 & 191 & 97 \\
\hline & Shizuoka & 7777 & 3700 & 476 & 140 \\
\hline & Aichi & 5172 & 7483 & 1447 & 317 \\
\hline & Mie & 5774 & 1816 & 314 & 96 \\
\hline \multirow{6}{*}{ Kinki } & Shiga & 4017 & 1413 & 352 & 45 \\
\hline & Kyoto & 4612 & 2610 & 566 & 111 \\
\hline & Osaka & 1905 & 8839 & 4640 & 294 \\
\hline & Hyogo & 8401 & 5535 & 659 & 162 \\
\hline & Nara & 3691 & 1364 & 370 & 57 \\
\hline & Wakayama & 4725 & 964 & 204 & 20 \\
\hline \multirow{5}{*}{ Chugoku } & Tottori & 3507 & 573 & 164 & 38 \\
\hline & Shimane & 6708 & 694 & 104 & 52 \\
\hline & Okayama & 7115 & 1922 & 270 & 146 \\
\hline & Hiroshima & 8479 & 2844 & 335 & 205 \\
\hline & Yamaguchi & 6112 & 1405 & 230 & 100 \\
\hline \multirow{4}{*}{ Shikoku } & Tokushima & 4147 & 756 & 182 & 70 \\
\hline & Kagawa & 1877 & 976 & 520 & 138 \\
\hline & Ehime & 5676 & 1385 & 244 & 215 \\
\hline & Kochi & 7104 & 728 & 103 & 70 \\
\hline \multirow{7}{*}{ Kyusyu } & Fukuoka & 4986 & 5102 & 1023 & 237 \\
\hline & Saga & 2441 & 833 & 341 & 24 \\
\hline & Nagasaki & 4132 & 1377 & 333 & 58 \\
\hline & Kumamoto & 7409 & 1786 & 241 & 84 \\
\hline & Oita & 6341 & 1166 & 184 & 57 \\
\hline & Miyazaki & 7735 & 1104 & 143 & 42 \\
\hline & Kagoshima & 9187 & 1648 & 179 & 53 \\
\hline Okinawa & Okinawa & 2281 & 1434 & 628 & 434 \\
\hline
\end{tabular}

Note: The figures for "Area” are from "2015 Statistical reports on the land area by prefectures and municipalities in Japan” by Geospatial Information Authority of Japan, Ministry of Land, Infrastructure, Transport and Tourism, Japan (http://www.gsi.go.jp/kihonjohochousa/kihonjohochousa60017.html), and the figures for "Population" are from "2015 Population Census of Japan” by Statistics Bureau, Ministry of Internal Affairs and Communications, Japan (http://www.stat.go.jp/english/data/kokusei/index.html). “Our sample size” means the sample size of households for each prefecture in our original dataset. 
Table 2. Type in the study

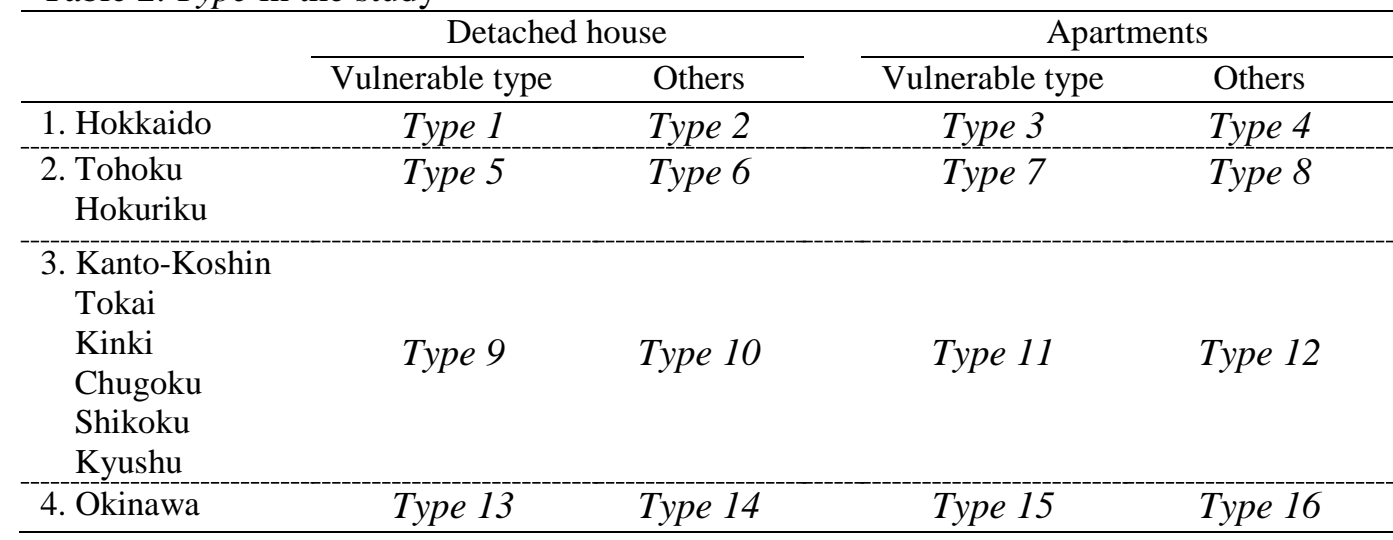

Note: "Vulnerable-type" households are those with elderly person(s). For details of the regions, also see Table 1 and Fig. 2.

Table 3. Descriptive statistics

\begin{tabular}{|c|c|c|c|c|}
\hline & $N$ & Median & Mean & Standard deviation \\
\hline $\begin{array}{l}\text { Household energy use } \\
\text { (in giga joules) }\end{array}$ & 5995 & 32.3 & 36.2 & 21.9 \\
\hline $\begin{array}{c}\text { Household energy expenses } \\
\text { (Japanese yen) }\end{array}$ & 5995 & 184424 & 200277 & 104035 \\
\hline $\begin{array}{c}\text { Number of household } \\
\text { members }\end{array}$ & 5995 & 2 & 2.55 & 1.45 \\
\hline \multicolumn{5}{|l|}{$\begin{array}{c}\text { Annual household income } \\
\text { (Japanese yen) }\end{array}$} \\
\hline 1. $\quad \sim 2500000$ & 1073 & - & - & - \\
\hline $2500000 \sim 5000000$ & 1974 & - & - & - \\
\hline $5000000 \sim 7500000$ & 1147 & - & - & - \\
\hline 4. $7500000 \sim 10000000$ & 698 & - & - & - \\
\hline 5. $10000000 \sim 15000000$ & 380 & - & - & - \\
\hline 6. $15000000 \sim 20000000$ & 71 & - & - & - \\
\hline 7. $20000000 \sim$ & 23 & - & - & - \\
\hline 8. Do not know & 169 & - & - & - \\
\hline 9. Denial of answer & 460 & - & - & - \\
\hline
\end{tabular}

Note: The figures of energy use and expenses are actual (not equivalized) annual data. 
Table 4. Energy use by type

\begin{tabular}{|c|c|c|c|c|}
\hline \multirow{3}{*}{ 1. Hokkaido } & \multicolumn{2}{|c|}{ Detached house } & \multicolumn{2}{|c|}{ Apartments } \\
\hline & Vulnerable type & Others & Vulnerable type & Others \\
\hline & $\begin{array}{cc}\text { Type } 1 & 48.0 \\
& (45.0)\end{array}$ & $\begin{array}{cc}\text { Type } 2 & 41.8 \\
& (39.7)\end{array}$ & $\begin{array}{rc}\text { Type } 3 & 29.5 \\
& (24.0)\end{array}$ & $\begin{array}{cc}\text { Type } 4 & 26.1 \\
& (22.4)\end{array}$ \\
\hline $\begin{array}{l}\text { 2. Tohoku } \\
\text { Hokuriku }\end{array}$ & $\begin{array}{rr}\text { Type } 5 & 35.3 \\
& (32.5)\end{array}$ & $\begin{array}{cc}\text { Type } 6 & 31.2 \\
& (29.3)\end{array}$ & $\begin{array}{cc} & \text { Type } 7 \\
& \\
& (19.4)\end{array}$ & $\begin{array}{cc}\text { Type } 8 & 18.7 \\
& (18.2)\end{array}$ \\
\hline $\begin{array}{l}\text { 3. Kanto-Kos } \\
\text { Tokai } \\
\text { Kinki } \\
\text { Chugoku } \\
\text { Shikoku } \\
\text { Kyushu }\end{array}$ & $\begin{array}{l}26.0 \\
(24.5)\end{array}$ & $\begin{array}{r}\text { Type } 1023.2 \\
\text { (21.8) }\end{array}$ & $\begin{array}{r}\text { Type } 1118.4 \\
\text { (17.0) }\end{array}$ & $\begin{array}{r}\text { Type } 1217.4 \\
\text { (16.7) }\end{array}$ \\
\hline 4. Okinawa & $\begin{array}{r}\text { Type } 1316.8 \\
(16.4)\end{array}$ & $\begin{array}{r}\text { Type } 1415.5 \\
\text { (14.9) }\end{array}$ & $\begin{array}{r}\text { Type } 1510.9 \\
(10.3)\end{array}$ & $\begin{array}{r}\text { Type } 1611.5 \\
(10.6)\end{array}$ \\
\hline
\end{tabular}

Note: The numbers are the means and medians (within parentheses) of energy use by type (in GJ).

"Vulnerable type" means households that include elderly person(s). For details of the regions, also see

Table 1 and Fig. 2.

Table 5. Energy poverty rates in Japan and its 10 regions

$$
\text { Energy poverty rate (\%) }
$$

\begin{tabular}{lrr}
\hline Entire Japan & 7.5 & 9.3 \\
- Hokkaido & 5.8 & 2.9 \\
- Tohoku & 9.4 & 6.3 \\
- Hokuriku & 8.3 & 7.4 \\
- Kanto-Koshin & 6.5 & 8.4 \\
- Tokai & 5.6 & 8.0 \\
- Kinki & 7.2 & 11.1 \\
- Chugoku & 9.0 & 8.4 \\
- Shikoku & 12.0 & 14.8 \\
- Kyushu & 10.4 & 12.7 \\
- Okinawa & 8.0 & 39.0
\end{tabular}

Note: The counterfactual energy poverty rate is the rate obtained with the use of a nationwide uniform threshold for the energy use dimension. 
Table 6. Poverty reduction effects of energy in Japan and its 10 regions

\begin{tabular}{|c|c|c|c|c|}
\hline \multirow{7}{*}{$\begin{array}{l}\text { All energy included } \\
\text { - without electricity } \\
\text { - without gas } \\
\text { - without kerosene }\end{array}$} & \multicolumn{2}{|c|}{ Hokkaido } & \multicolumn{2}{|c|}{ Tohoku } \\
\hline & \multirow{2}{*}{$\begin{array}{l}\text { Energy poverty rate (\%) } \\
5.8\end{array}$} & Difference (\%) & Energy poverty rate (\%) & Difference (\%) \\
\hline & & - & 9.4 & - \\
\hline & 19.4 & 13.6 & 26.6 & 17.2 \\
\hline & 21.7 & 15.9 & 22.7 & 13.3 \\
\hline & 45.2 & 39.4 & 41.4 & 32.0 \\
\hline & \multicolumn{2}{|c|}{ Hokuriku } & \multicolumn{2}{|c|}{ Kanto-Koshin } \\
\hline & Energy poverty rate (\%) & Difference (\%) & Energy poverty rate (\%) & Difference (\%) \\
\hline All energy included & 8.3 & - & 6.5 & - \\
\hline - without electricity & 32.1 & 23.8 & 27.5 & 21.0 \\
\hline - without gas & 21.3 & 13.0 & 30.5 & 24.0 \\
\hline \multirow[t]{3}{*}{ - without kerosene } & 24.2 & 15.9 & 9.9 & 3.4 \\
\hline & \multicolumn{2}{|c|}{ Tokai } & \multicolumn{2}{|c|}{ Kinki } \\
\hline & Energy poverty rate (\%) & Difference (\%) & Energy poverty rate (\%) & Difference (\%) \\
\hline All energy included & 5.6 & - & 7.2 & - \\
\hline - without electricity & 27.0 & 21.4 & 33.8 & 26.6 \\
\hline - without gas & 25.7 & 20.1 & 37.8 & 30.6 \\
\hline \multirow[t]{3}{*}{ - without kerosene } & 11.7 & 6.1 & 10.4 & 3.2 \\
\hline & \multicolumn{2}{|c|}{ Chugoku } & \multicolumn{2}{|l|}{$\begin{array}{r}\text { Shikoku } \\
\end{array}$} \\
\hline & Energy poverty rate (\%) & Difference (\%) & Energy poverty rate (\%) & Difference (\%) \\
\hline All energy included & 9.0 & - & 12.0 & -2 \\
\hline - without electricity & 37.9 & 28.9 & 48.4 & 36.4 \\
\hline - without gas & 26.6 & 17.6 & 29.6 & 17.6 \\
\hline \multirow[t]{3}{*}{ - without kerosene } & 16.0 & 7.0 & 24.4 & 12.4 \\
\hline & \multicolumn{2}{|c|}{ Kyushu } & \multicolumn{2}{|c|}{ Okinawa } \\
\hline & Energy poverty rate (\%) & Difference (\%) & Energy poverty rate (\%) & Difference (\%) \\
\hline All energy included & 10.4 & - & 8.0 & - \\
\hline - without electricity & 42.1 & 31.7 & 61.4 & 53.4 \\
\hline - without gas & 29.5 & 19.1 & 31.1 & 23.1 \\
\hline \multirow{3}{*}{ - without kerosene } & 19.4 & 9.0 & 10.4 & 2.4 \\
\hline & \multicolumn{2}{|c|}{ Entire Japan } & & \\
\hline & Energy poverty rate (\%) & Difference (\%) & & \\
\hline All energy included & 7.5 & - & & \\
\hline - without electricity & 31.3 & 23.8 & & \\
\hline - without gas & 29.6 & 22.1 & & \\
\hline - without kerosene & 16.2 & 8.7 & & \\
\hline
\end{tabular}

